\title{
Differential Activation of Adenylyl Cyclases by Spatial and Procedural Learning
}

\author{
Jean-Louis Guillou, Gregory M. Rose, and Dermot M. F. Cooper \\ Department of Pharmacology, University of Colorado Health Sciences Center, Denver, Colorado 80262
}

\begin{abstract}
Adenylyl cyclases (ACs) are involved in a variety of advanced CNS functions, including some types of learning and memory. At least nine $\mathrm{AC}$ isoforms are expressed in the brain, which are divisible into three broad classes based on the ability of $\mathrm{Ca}^{2+}$ to modulate their activity. This study examined the hypothesis that different learning tasks would differentially activate ACs in selected brain regions. The ability of forskolin or $\mathrm{Ca}^{2+}$ to enhance AC activity in the hippocampus, parietal cortex, striatum, and cerebellum was examined after mice had been trained in either a spatial or procedural learning task using a Morris water maze. Sensitivity of ACs to forskolin was enhanced to a greater degree in most brain regions after procedural learning, but
\end{abstract}

One approach to identifying key molecular elements implicated in learning-memory processes has emerged from studies in invertebrates. In Aplysia and Drosophila, adenylyl cyclases (ACs) have been shown to be essential for the acquisition of associative learning (Dudai et al., 1976; Kandel and Schwartz, 1982). During this past decade, nine isoforms of mammalian adenylyl cyclases have been identified and characterized (for review, see Cooper et al., 1994, 1995). Each AC isoform possesses unique properties, particularly with respect to the modulation of their activity by calcium $\left(\mathrm{Ca}^{2+}\right)$. Several ACs are expressed in the brain, but their mRNAs are differentially distributed within brain regions. For example, the $\mathrm{Ca}^{2+}$-insensitive $\mathrm{AC} 2$ is widely distributed throughout the entire brain. In contrast, the $\mathrm{Ca}^{2+}$-inhibited AC5 is limited to the striatum, whereas the $\mathrm{Ca}^{2+}$-stimulated $\mathrm{AC} 1$ is concentrated in the hippocampus, the cerebellum, and neocortical areas (Xia et al., 1991; Mons and Cooper, 1995; Mons et al., 1998).

Storm and colleagues have recently hypothesized a common role for $\mathrm{Ca}^{2+}$-stimulated ACs of mammalian species and invertebrates in neuroplasticity and in learning and memory formation (Xia et al., 1995). However, the available data do not provide unequivocal support for this notion. It has been shown that intrahippocampal infusion of 8-Bromo-cAMP or forskolin (FK), activators of AC, enhanced, whereas KT5720, a specific inhibitor of cAMP-modulated protein kinase A (PKA), hindered memory

\footnotetext{
Received March 3, 1999; revised May 3, 1999; accepted May 5, 1999.

This work was supported by National Institute on Aging Grant AG 10755 to G.M.R., National Institute of Health Grant NS 28389 to D.M.F.C., and a fellowship from the Foundation F YSSEN (Paris) to J.-L.G. We thank Dr. R. Jaffard for helpful comments and suggestions on this manuscript.

Correspondence should be addressed to Dr. Guillou's present address: Laboratoire de Neurosciences Comportementales et Cognitives, Université Bordeaux I, Unité Mixte de Recherche 5807, Avenue des Facultés, 33405 Talence Cedex, France.

Dr. Rose's present address: Neuroscience Drug Discovery, Department 404, Bristol-Myers Squibb, 5 Research Parkway, Wallingford, CT 06492.

Copyright (C) 1999 Society for Neuroscience 0270-6474/99/196183-08\$05.00/0
}

$\mathrm{Ca}^{2+}$-sensitive ACs in the hippocampus were more sensitive to spatial learning. Because nonspecific behavioral elements, such as stress or motor activity, were similar in both experimental tasks, these results provide the first evidence that acquisition of different kinds of learning is associated with selective changes in particular AC species in a mammalian brain and support the idea that different biochemical processing, involving particular isoforms of ACs, subserves different memory systems.

Key words: adenylyl cyclase; calcium; spatial learning; procedural learning; memory systems; water maze; mice consolidation in a passive avoidance task in rat (Bernabeu et al., 1997). Moreover, a correlative study has demonstrated that cAMP levels and PKA activity increased in the hippocampus after passive avoidance training (Bernabeu et al., 1997). In accordance with these results, we recently reported that the AC activity was upregulated in the hippocampus after the acquisition of a bar-pressing task in mice (Guillou et al., 1998). However, our laboratory has also observed a downregulation of the AC activity in the hippocampus after the acquisition of a spatial discrimination task in the radial maze (Guillou et al., 1998). Furthermore, studies of knock-out mice lacking AC1 show only a marginal impairment of spatial learning ability (Wu et al., 1995). Together, these results suggest that the nature of the learning task may be important in determining how the hippocampal cAMP signaling pathway responds to behavioral experience.

To further investigate this idea, we trained mice in a spatial or a procedural version of a water maze task, using experimental designs that allowed direct comparisons. The spatial version of the task is known to require the hippocampus (Morris et al., 1982; Moser et al., 1995). The procedural task, on the other hand, could not be solved using spatial information and is similar to other tasks that have been shown to be unaffected by hippocampal lesions (Morris et al., 1986). Our specific hypothesis was that training in the two different tasks would cause differential activation of $\mathrm{Ca}^{2+}$-sensitive versus $\mathrm{Ca}^{2+}$-insensitive $\mathrm{AC}$ activities in the hippocampus. Therefore, generalized stimulation of AC types by FK (McHugh Sutkowski et al., 1994) was compared with type-selective stimulation by $\mathrm{Ca}^{2+}$ (targeting $\mathrm{AC} 1$ and $\mathrm{AC} 8$ ). In addition, because other brain areas have been suggested to be differentially involved in these two kinds of learning [e.g., the parietal cortex for spatial learning (DiMattia and Kesner, 1988; Save et al., 1992), the striatum and the cerebellum for procedural learning (Knowlton et al., 1996; Thompson and Kim, 1996; White, 1997)], the effects of the two types of training on AC activity in these regions was also examined. 


\section{REGULAR TRAINING}

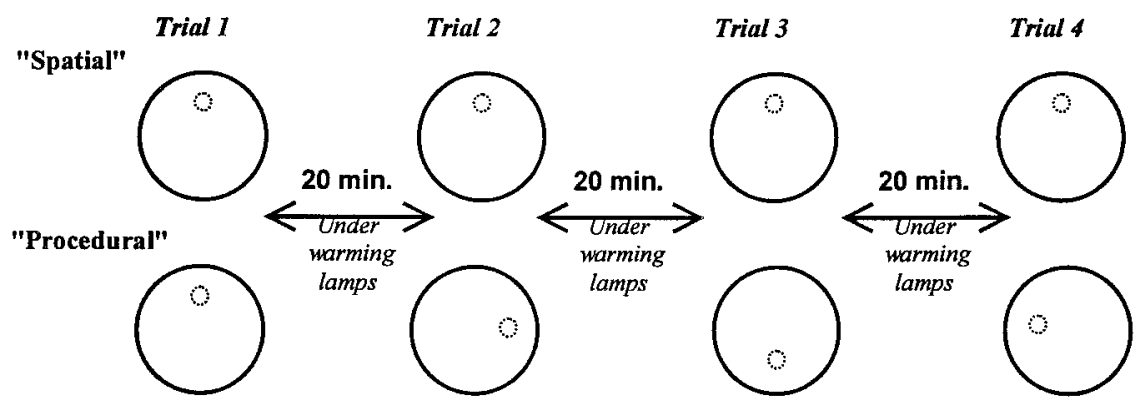

\section{LAST SESSION}

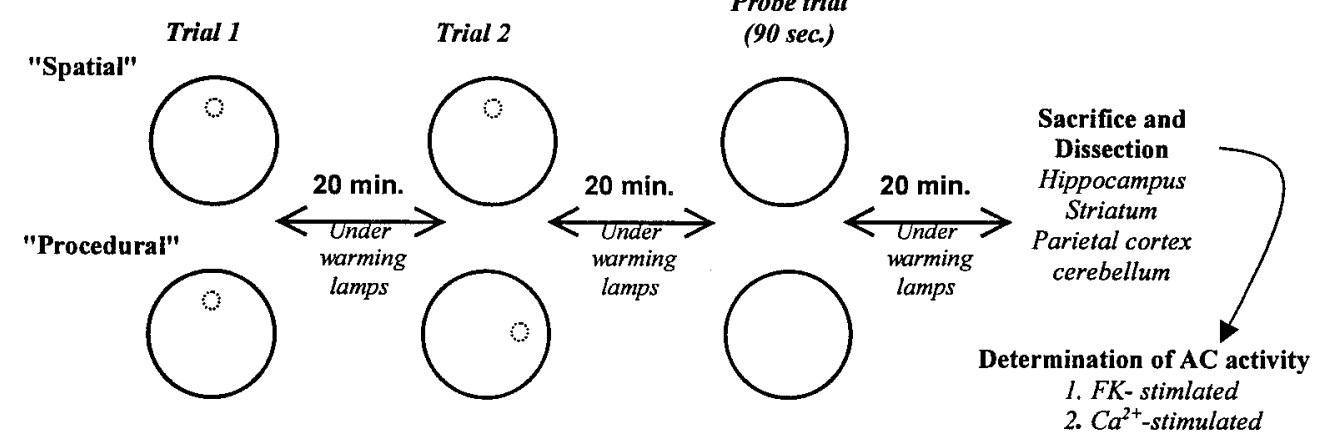

Figure 1. Schematic representation of the protocol. See Materials and Methods for explanations and details.

2. $\mathrm{Ca}^{2+}$-stimulated

\section{MATERIALS AND METHODS}

Animals. Male C57BL/6 mice (The Jackson Laboratory, Bar Harbor, $\mathrm{ME}$ ), 10 weeks old, were housed in groups of four in polycarbonate cages with access to food and water ad libitum. Air temperature in the animal colony was maintained at $23^{\circ} \mathrm{C}$, and the mice were exposed to $12 \mathrm{hr}$ of light each day (lights on from 7:00 A.M. to 7:00 P.M.). Before behavioral training was begun, the mice were weighed and handled daily for $5 \mathrm{~d}$.

Water maze training. The training apparatus was a $1.5 \mathrm{~m}$ diameter pool filled with water that was heated to $27^{\circ} \mathrm{C}$ and made opaque with white Createx, a nontoxic latex paint. The pool was surrounded by numerous visual cues that were kept in constant locations during the entire training period. The mice were trained in either a spatial learning task $(n=12)$ or a procedural learning task $(n=11)$. In either case, the animal had to swim until it located an escape platform that was submerged $\sim 0.5 \mathrm{~cm}$ below the surface of the water. For the spatial learning task, the escape platform was placed in the "center" of one of four imaginary quadrants of the pool and kept in this location throughout training. For the procedural learning task, the location of the platform was randomly varied between the four quadrants but was always placed in the center of the quadrant.

The training protocol is summarized in Figure 1. All mice were given four daily trials, with an intertrial interval of $20 \mathrm{~min}$, each day for $9 \mathrm{~d}$. For each trial, the mouse was placed into the pool from one of four randomly varied start positions located around the rim of the pool and was then given a maximum of $90 \mathrm{sec}$ to swim to find the escape platform. If the animal found the platform, it was allowed to rest on it for $15 \mathrm{sec}$ before being removed from the pool and placed back into its home cage. If a mouse did not locate the platform within $90 \mathrm{sec}$, the animal was hand guided to it. During the intertrial delay, the mice were kept under warming lamps. On the 10th training day, the animals were given only two regular trials, followed by a probe trial. During the probe trial, the platform was removed from the pool, and all mice swam for $90 \mathrm{sec}$. Swim times and distances were recorded and analyzed using an automated tracking system (San Diego Instruments, San Diego, CA).

Neurochemistry. After the probe trial, the mice were placed under the warming lamps as in an intertrial delay and were killed 20 min later for measurements of brain adenylyl cyclase activity. Another group of mice (quiet control group; $n=6$ ), which had been weighed and handled but not exposed to the water maze, were killed immediately after removal from their home environment.

The animals were killed by decapitation, after which the brain was quickly removed, and the hippocampus, the striatum, the parietal cortex, and the cerebellum were dissected out and frozen on dry ice. Like samples from each group were pooled and then homogenized in $20 \mathrm{vol}$ of a cold buffer containing $50 \mathrm{~mm}$ Tris, $\mathrm{pH} 7.4,1 \mathrm{~mm}$ EGTA, and 10\% sucrose, to which a mixture of protease inhibitors was added (for review, see Ahlijanian and Cooper, 1988). This preparation was centrifuged at $1000 \times g$ for $10 \mathrm{~min}$, after which the supernatant was further centrifuged at $15,000 \times g$ for $10 \mathrm{~min}$. The resulting pellet was washed into the homogenization buffer and centrifuged again three times. The final pellet was stored in liquid nitrogen until the adenylyl cyclase assays were performed.

Immediately before assay, the pellets were washed and centrifuged again, after which they were suspended into a sufficient volume of buffer to give a protein concentration in the range of $1 \mathrm{mg} / \mathrm{ml}$ (Lowry et al., 1951). Adenylyl cyclase activity was quantified by determining the rate of conversion of ATP to cAMP. This enzymatic activity was assayed in a $100 \mu \mathrm{l}$ volume containing, in final concentration, $25 \mathrm{~mm}$ Tris, $\mathrm{pH}$ 7.4, 60 $\mu \mathrm{M}$ EGTA, $10 \mathrm{~mm}$ isobutyl-methyl-xanthine, $5 \mathrm{~mm}$ phosphocreatine, 50 $\mathrm{U} / \mathrm{ml}$ creatine phosphokinase, $0.1 \mathrm{~mm}$ GTP, $0.1 \mathrm{mM}$ ATP, $1 \mathrm{mM}$ cAMP, and $1.5 \mu \mathrm{Ci} \alpha^{32} \mathrm{P}$-ATP. Stimulation of AC activity was produced by addition of various concentrations of FK (Sigma, St. Louis, MO) or calcium. The concentration of free calcium was calculated as described by Ahlijanian and Cooper (1988). The reaction was initiated by the addition of the membrane preparation ( $\sim 10 \mu \mathrm{g}$ of protein) and was performed at $30^{\circ} \mathrm{C}$. After $30 \mathrm{~min}$, the reaction was terminated by the addition of $1.0 \mathrm{ml}$ of a stopping solution containing $50 \mathrm{~mm}$ Tris, $2.6 \mathrm{~mm}$ ATP, $4.3 \mathrm{~mm}$ cAMP, $10 \mathrm{mM} \mathrm{CaCl}_{2}$, and $0.5 \%$ lauryl sulfate. Separation of ATP from cAMP was then performed using Dowex and alumina columns according to the procedure of Salomon et al. (1974). Tritiated cAMP $(\sim 10,000$ $\mathrm{cpm}$ ) was included to monitor cAMP recovery from the samples. The ${ }^{32} \mathrm{P}$-cAMP formed during the reaction was quantified, and after determination of the protein concentration, the enzymatic activity was expressed in picomoles per minute and per milligram of protein. Each measure was the mean of a triplicate determination, and each assay was repeated at least twice.

\section{RESULTS}

\section{Behavior}

Acquisition

Mice trained in either the spatial or procedural learning paradigms learned to find the hidden escape platform faster with 
practice, as was evident by a decrease in the swim times recorded over sessions (Fig. 2A). A repeated measures ANOVA performed on these data showed a significant effect of the group $\left(F_{(1,21)}=\right.$ $23.8 ; p<0.001)$ and sessions $\left(F_{(9,189)}=23.78 ; p<0.001\right)$ but no significant interaction. Post hoc analyses (Scheffe $F$ test) revealed that the swim latencies decreased significantly for both the spatial $\left(F_{(9,99)}=23.6 ; p<0.001\right)$ and procedural $\left(F_{(9,90)}=7.1 ; p<\right.$ $0.001)$ groups. However, a difference between groups was observed as early as during the first four trials of the initial training session. Mice trained in the spatial task found the platform more quickly than those trained in the procedural task $\left(F_{(1,21)}=5.6\right.$; $p<0.02$ ). Because swim speed was not found to be different for the two groups $(p>0.22)$ (Fig. $2 B)$, analyses of swim distances (data not shown) revealed the same pattern of effects described for swim latencies.

\section{Probe trial}

For the last swim trial of session 10, the escape platform was removed from the pool. Under this condition, the mice trained in the spatial learning paradigm spent significantly more time searching the area of the pool where the platform had been located $(p<0.001)$ (Fig. $2 C)$. In contrast, the animals trained in the procedural version of the task did not show any localization of their swimming pattern. This difference in probe trial performance was mirrored in the swim paths shown by the mice over successive training days. As is shown in Figure 3, the path of animals in the spatial group quickly became oriented toward the location of the escape platform, with progressively better accuracy over days. In sharp contrast, most animals trained in the procedural task developed a circular pattern of swimming at a distance from the wall of the pool that was optimized to encounter the platform. These different swim strategies, developed during the training sessions, were clearly expressed during the probe trial (Fig. 3).

\section{Neurochemistry}

\section{Effect of training on forskolin-stimulated AC activity}

Baseline AC activity was found to be somewhat higher in the striatum than in the hippocampus, parietal cortex, or cerebellum. All regions responded to increasing concentrations of forskolin with progressive increases in AC activity. In general, training was observed to enhance both resting and forskolin-stimulated AC activity. However, the effects showed some variation as a function of the training procedure and brain region (Fig. 4). Specifically, after procedural learning, AC activity was greatly increased compared with quiet control group in the hippocampus, striatum, cerebellum, and, to a lesser extent, in the parietal cortex. Increased AC activity was also seen after spatial learning. However, in this case, a significant change was not observed in the parietal cortex.

A two-way ANOVA performed on these data revealed significant effects between the groups $\left(F_{(2,23)}=187.4 ; p<0.001\right)$ and between brain regions $\left(F_{(3,23)}=31.5 ; p<0.001\right)$, as well as a groups $\times$ region interaction $\left(F_{(6,23)}=10.6 ; p<0.001\right)$. Post hoc comparisons revealed that increases in forskolin-stimulated AC activity were significantly greater after procedural, compared with spatial learning for the hippocampus and the striatum $(p<$ 0.01 for each). However, the effective concentration of forskolin giving $50 \%$ of the response $\left(\mathrm{EC}_{50}\right), 3.7 \pm 0.3 \mu \mathrm{M}$ as determined using nonlinear fitting analyses (Inplot4; Graphpad Software Inc.), was not altered by behavioral training.

\section{Effect of training on calcium-stimulated AC activity}

In general, the effects of behavioral experience on $\mathrm{Ca}^{2+}$ stimulated AC activity paralleled what was seen for forskolin stimulation (Fig. 5). Procedural training tended to have greater effects than spatial training. However, neither procedural nor spatial learning affected $\mathrm{Ca}^{2+}$-stimulated AC activity in the parietal cortex, and increased stimulation in the cerebellum was seen only after procedural training. Interestingly, whereas $\mathrm{Ca}^{2+}$ inhibited striatal AC activity in the quiet control group, $\mathrm{Ca}^{2+}$ dependent stimulation was seen in both trained groups. Finally, in sharp contrast to other brain regions, the increase in hippocampal $\mathrm{Ca}^{2+}$-sensitive AC activity was greater after spatial training than after procedural training at $\mathrm{Ca}^{2+}$ levels of $0.2 \mu \mathrm{M}$ or more.

A two-way ANOVA performed on these data revealed significant effects between groups $\left(F_{(2,23)}=140.2 ; p<0.001\right)$ and brain regions $\left(F_{(3,23)}=58.6 ; p<0.001\right)$ and a group $\times$ region interaction $\left(F_{(6,23)}=31.0 ; p<0.001\right)$. Post hoc comparison revealed significant differences between the spatial and procedural learning groups for the striatum and the cerebellum $(p<0.001$ for each). Curves describing the data were best fit using a twocomponent model in which the low- and high-affinity sites for $\mathrm{Ca}^{2+}$ were $0.06 \pm 0.02 \mu \mathrm{M}$ (stimulatory site) and $0.03 \mathrm{mM} \pm 0.01$ (inhibitory site, not shown on the curve), respectively. This analysis did not reveal alterations in the $\mathrm{EC}_{50}$ for $\mathrm{Ca}^{2+}$ stimulation of $\mathrm{AC}$ activity by training in any brain region.

\section{Differential effects of procedural versus spatial training}

The effects of behavioral training on forskolin- and $\mathrm{Ca}^{2+}$ stimulated AC activity in the brain regions assayed are summarized in Figure 6. Although both training procedures tended to increase the responsiveness of $\mathrm{AC}$ to either forskolin or $\mathrm{Ca}^{2+}$, this effect was markedly less in the parietal cortex than in the other brain areas. With the exception of $\mathrm{Ca}^{2+}$-stimulation of $\mathrm{AC}$ activity in the hippocampus, procedural training produced a greater increase in AC activity than spatial training (Fig. 6A). In the hippocampus, spatial training resulted in greater increases in $\mathrm{Ca}^{2+}$-stimulated AC activity than did procedural training, although an opposite effect was seen with forskolin. Furthermore, this increase was not observed until submicromolar concentrations of $\mathrm{Ca}^{2+}(\geq 0.2 \mu \mathrm{M})$ were used (Fig. $\left.6 B\right)$.

\section{DISCUSSION}

The primary results of this study can be summarized as follows. First, consistent with what has been reported by others (Moser et al., 1995), mice were able to learn to find a hidden escape platform sooner, and with significantly better accuracy, when the platform remained in a constant rather than a randomly changing location. Analysis of the swim paths of the mice showed that animals trained in the two different paradigms learned to find the platform by using different strategies, which we have termed spatial and procedural. Second, the modulation of AC activity by either $\mathrm{FK}$ or $\mathrm{Ca}^{2+}$ was consistently increased in the hippocampus, striatum, and cerebellum after training compared with untrained controls. However, the hippocampus was the only brain region in which spatial and procedural training produced divergent responses in $\mathrm{FK}$ - versus $\mathrm{Ca}^{2+}$-sensitive $\mathrm{AC}$ activity. This finding indicates that, in the hippocampus, $\mathrm{Ca}^{2+}$-insensitive and $\mathrm{Ca}^{2+}$-stimulated ACs were differentially regulated as a function of the type of learning in which the animals were engaged. Because the experimental context, as well as the motor demand before the biochemical measure (probe trial), was identical in the two groups, it is unlikely that effects of nonspecific behaviors, 

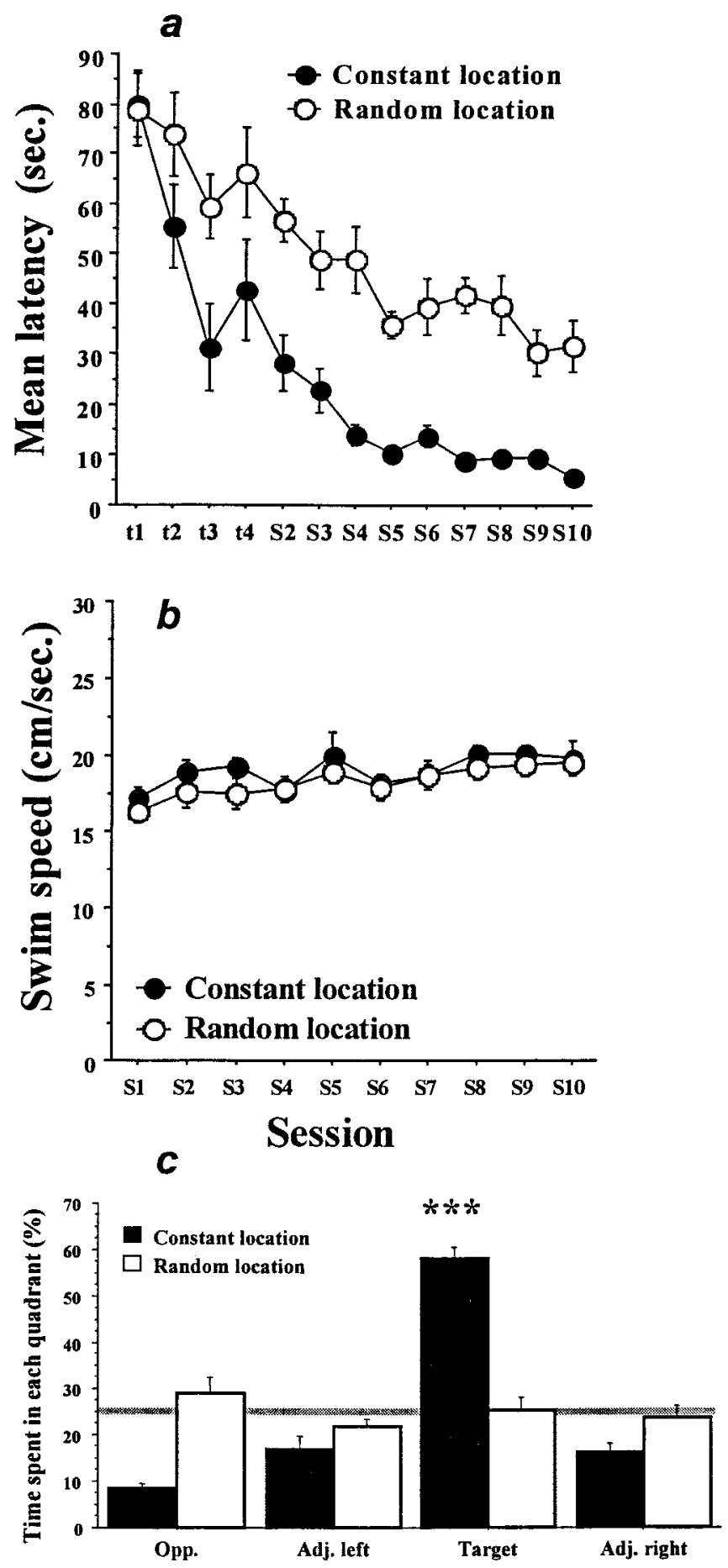

Figure 2. Acquisition of the learning tasks. $A$, Swim latencies (mean \pm SEM) to find the hidden escape platform for the groups of mice trained in either the spatial task (constant location, filled circles) or the procedural task (random location, open circles). The first four data points (t1-t4) are the values for the individual trials of training session 1 . The remaining data $(S 2-S 10)$ are the means of four daily trials. Although the two groups performed similarly on the first training trial, mice trained in the spatial task showed more rapid and greater improvement overall. $B$, Swim speeds (mean \pm SEM) for the two groups across training sessions. Swim speeds were never different and therefore could not have contributed to the greater reduction in swim times seen in the spatial learning group. $C$, Probe trial performance. Each bar represents the percentage of swim time spent in one of the four quadrants of the pool during a $90 \mathrm{sec}$ swim with the escape platform removed. Target, Quadrant where the platform was constantly located for the spatial group; Opp., quadrant opposite the

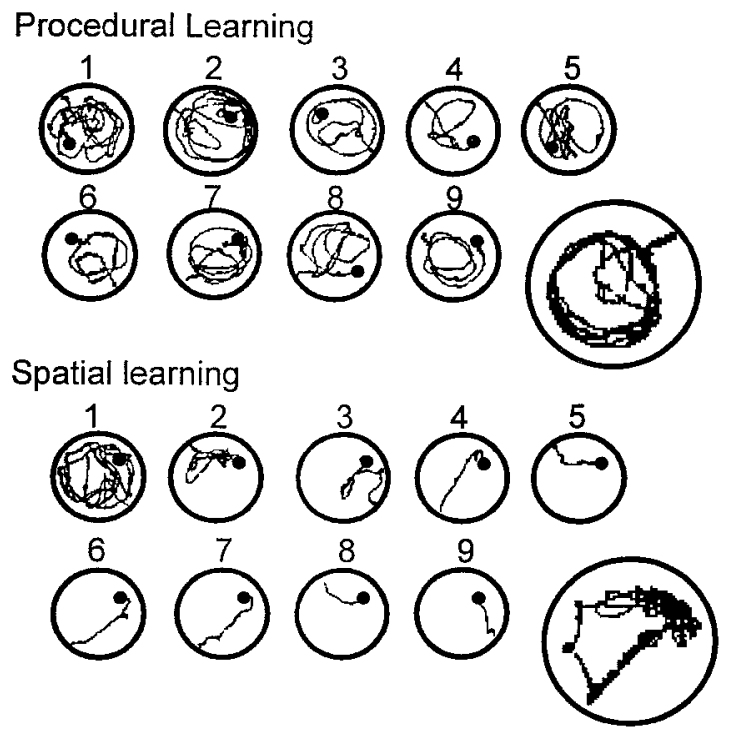

Figure 3. Swim paths during procedural and spatial learning. Each small circle illustrates a representative swim path recorded during each of the nine training sessions. The large circles show examples of swim paths recorded during the probe trial. The location of the hidden platform is indicated by the black dots. Mice trained in the procedural task tended to learn to swim in a circular path at a distance from the wall of the pool that optimized the chance of bumping into the platform. This strategy was particularly clear during the probe trial. Mice trained in the spatial task were soon able to swim directly to the location of the platform from any starting point. The swim track recorded during the probe trial provided a clear indication of a search predominantly localized to where the platform had been located during training.

such as stress or locomotor activity, could explain this differential activation.

\section{Dissociation between learning-induced changes in AC activity in different brain regions}

Accumulating data have provided evidence that memory is not a unitary entity but is organized in multiple systems involving distinct brain areas or circuitries (Schacter and Tulving, 1994). Several dual theories suggest a selective role for the hippocampus in a higher-order form of memory, such as spatial learning (O'Keefe and Nadel, 1978; Jarrard, 1993), declarative memory (Squire, 1992), or processes underlying the establishment of relational representations (Sutherland and Rudy, 1989; Eichenbaum et al., 1994). In contrast, hippocampal-independent mechanisms posited to be involved in simpler forms of learning have been suggested to bring into play brain structures involved in the motor function, such the striatum and the cerebellum (Packard et al., 1989; Knowlton et al., 1996; Thompson and Kim, 1996; White, 1997).

Our present findings are in agreement with the idea of multiple memory systems in that learning-related changes in AC activity depended on the brain region, the task, and the type of AC itself. For example, increases in FK modulation of AC activity occurred after either spatial or procedural training in the hippocampus,

$\leftarrow$

target quadrant; Adj. left, Adj. right, quadrants adjacent the target quadrant. Mice trained in the spatial task spent significantly more time during the probe trial in the target quadrant, whereas mice trained in the procedural task showed no selectivity in their search pattern. The gray line indicates the level of performance expected by chance. ${ }^{* * *} p<0.001$. 

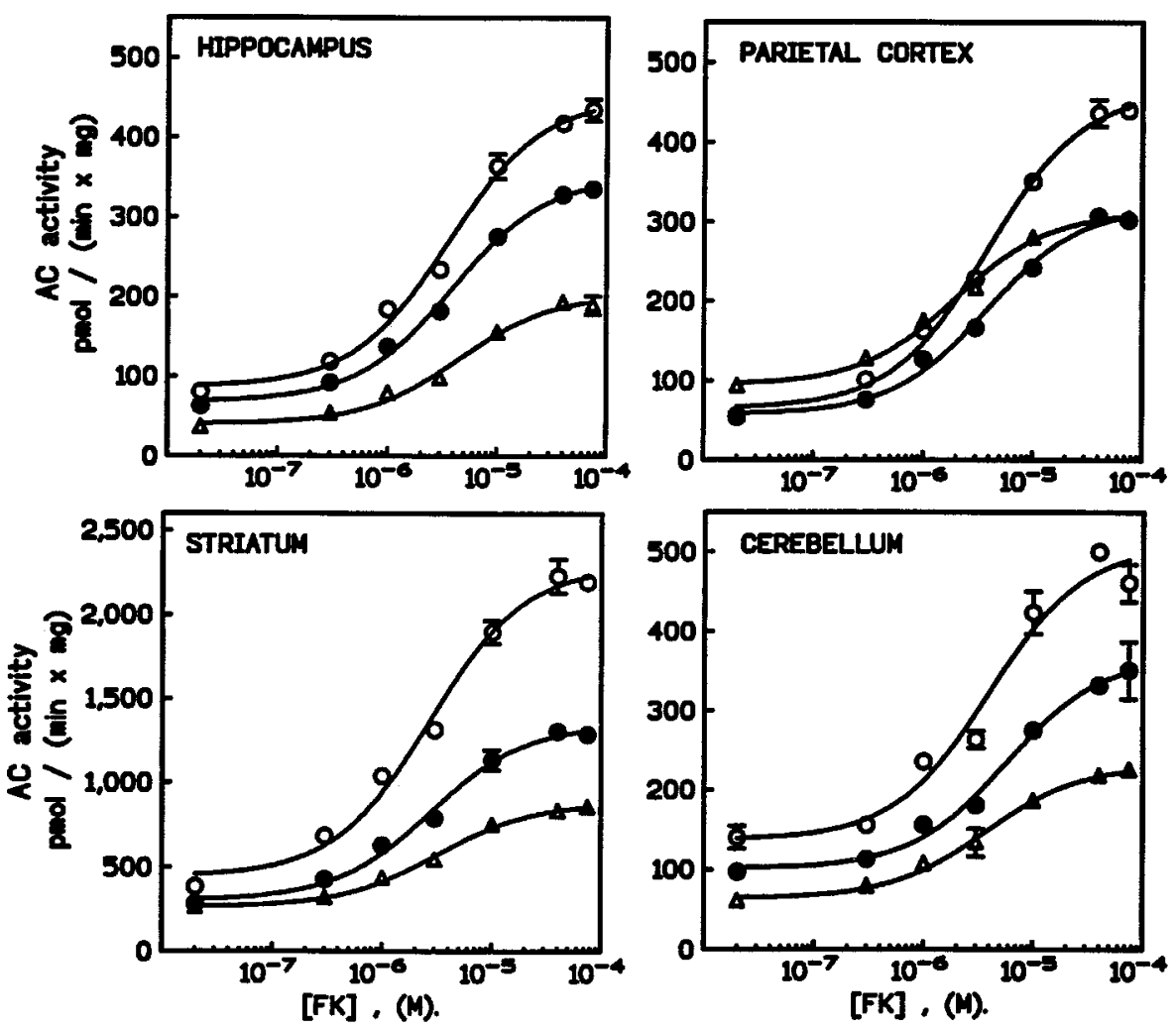

Figure 4. Effects of spatial or procedural learning on forskolin-stimulated adenylyl cyclase activity. For each brain region, the graph shows the effect of increasing concentrations of forskolin (from $20 \mathrm{nM}$ to $90 \mu \mathrm{M}$ ) on AC activity in membrane preparations obtained from mice trained in the procedural (open circles) or the spatial (filled circles) task or the control group (triangles). Data shown are the mean \pm SEM of triplicate samples and are representative of two determinations. Behavioral training resulted in increased sensitivity of $\mathrm{AC}$ to forskolin in most brain regions assayed. In all cases, the magnitude of the response was greater for mice trained in the procedural task than in the spatial task.
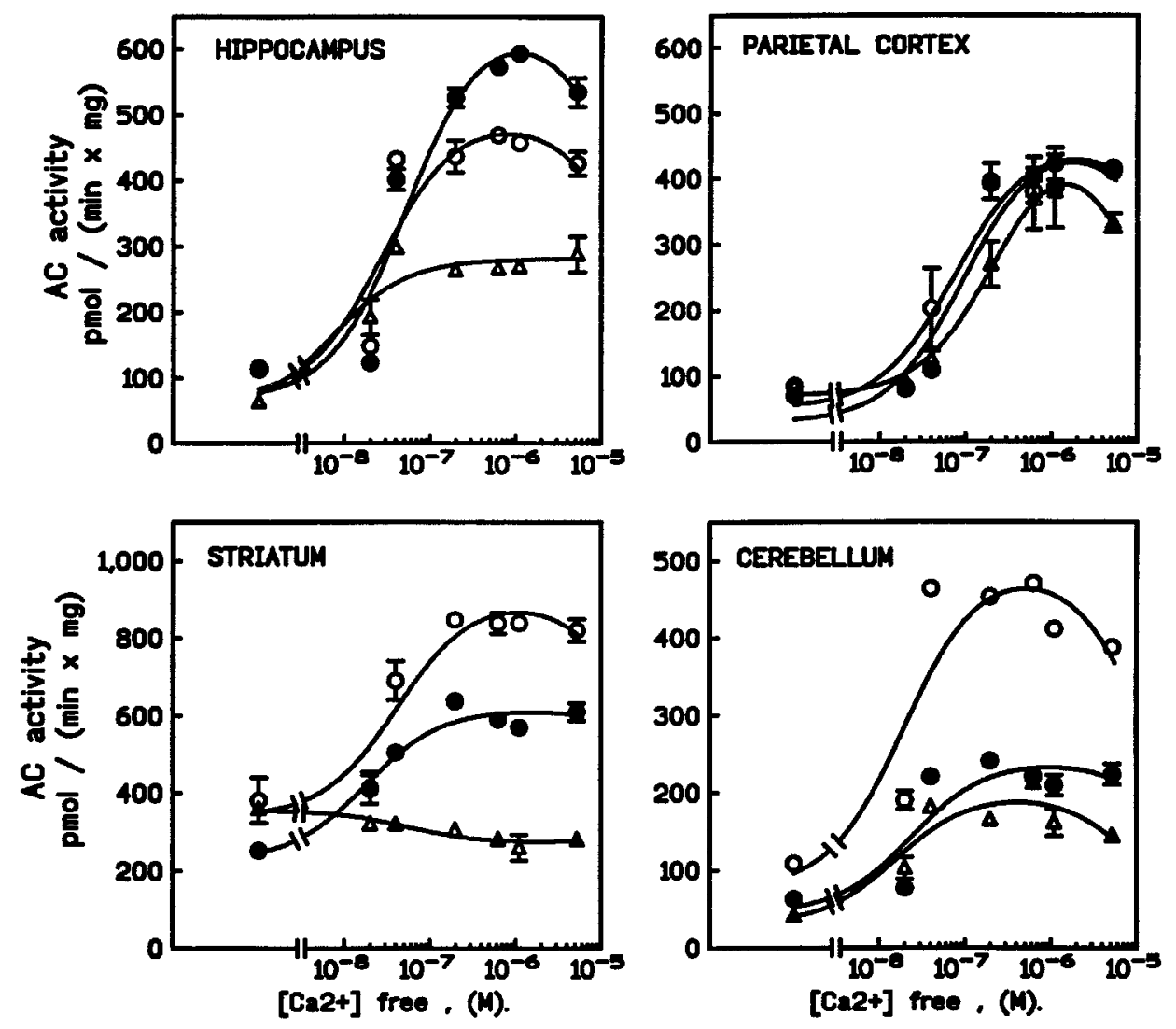

Figure 5. Effects of spatial or procedural learning on calcium-stimulated adenylyl cyclase activity. For each brain region, the graph shows the effect of increasing concentrations of $\mathrm{Ca}^{2+}$ (from 0.0 to $6.0 \mu \mathrm{M}$ ) on $\mathrm{AC}$ activity in membrane preparations obtained from mice trained in the procedural (open circles) or the spatial (filled circles) task or the control group (triangles). Data shown are the mean \pm SEM of triplicate samples and are representative of two determinations. Behavioral training resulted in increased sensitivity of AC to calcium in all regions but parietal cortex. When observed, the magnitude of the response was greater for mice trained in the procedural task than in the spatial task, with the notable exception of the hippocampus.

striatum, and cerebellum but not after spatial training in the parietal cortex (discussed further below). In all brain regions, procedural training produced a larger increase in the sensitivity of ACs to FK than did spatial training. A very different pattern of results was observed for $\mathrm{Ca}^{2+}$-sensitive ACs. In this case, neither type of training altered the response to $\mathrm{Ca}^{2+}$ in the parietal cortex. No response in $\mathrm{Ca}^{2+}$-sensitive $\mathrm{AC}$ activity was observed after spatial training in the cerebellum. In the striatum, both 

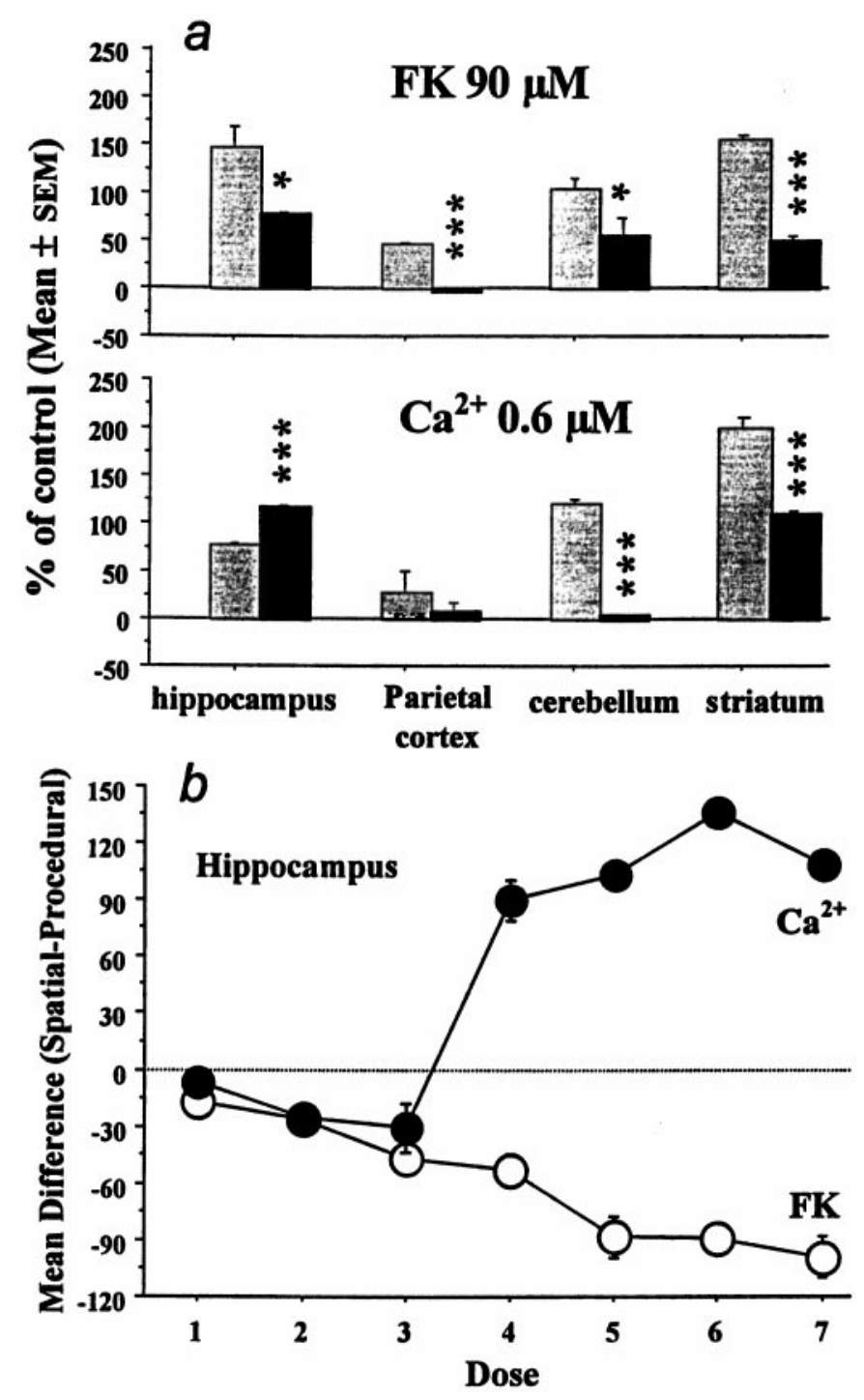

Figure 6. Comparison of task-dependent changes in forskolin- and calcium-dependent adenylyl cyclase activity. $A$, Changes observed after procedural (shaded bars) or spatial (black bars) learning in the different brain regions. Data are shown for concentrations of $\mathrm{FK}$ and $\mathrm{Ca}^{2+}$ at which maximal stimulation of $\mathrm{AC}$ was observed. Procedural training uniformly resulted in larger increases in FK-dependent AC stimulation than did spatial training. Similar results were seen in the cerebellum and striatum for $\mathrm{Ca}^{2+}$-dependent AC. However, spatial training produced the larger increase in $\mathrm{Ca}^{2+}$-dependent $\mathrm{AC}$ in the hippocampus. ${ }^{*} p<0.05$; ${ }^{* * *} p<0.001$, indicates significant differences between the two groups, respectively. $B$, Illustration of the dose-dependent nature of the differential response of hippocampal ACs to forskolin and calcium after spatial or procedural training. FK concentrations ranged from $20 \mathrm{nM}$ to $90 \mu \mathrm{M}$, whereas $\mathrm{Ca}^{2+}$ concentrations were stepped from 0.0 to $6.0 \mu \mathrm{M}$. For FK, the decrease in AC activity seen with spatial learning was dosedependent. A similar relationship was seen for $\mathrm{Ca}^{2+}$ at low concentrations but was reversed once the $\left[\mathrm{Ca}^{2+}\right]$ rose to $0.2 \mu \mathrm{M}$. At these higher $\mathrm{Ca}^{2+}$ concentrations, a much greater increase in AC activity was seen after spatial training.

types of training altered the response of ACs from inhibiting to enhancing activity. However, whereas procedural training produced a larger enhancement than spatial training in the response of $\mathrm{Ca}^{2+}$-sensitive ACs in the striatum and cerebellum, the opposite result was seen in the hippocampus. Notwithstanding the differences just described, it is clear that either spatial or proce- dural training resulted in overlap in the types of changes observed in AC activity. This result is not unexpected, because it is unlikely that these two complex learning tasks rely entirely on a single memory system.

The results of several studies using lesion techniques have suggested a role for parietal cortex in spatial learning or memory (Save et al., 1992). In this context, it is noteworthy that the present study did not reveal any alterations in AC activity in the parietal cortex after spatial learning. Because it is unlikely that learning in this task did not, to at least some extent, involve parietal areas (Kolb and Walkey, 1986), it is reasonable to conclude that ACs do not play a critical role in spatial information processing by the parietal cortex.

\section{Learning induces a shift from $\mathrm{Ca}^{2+}$-inhibited to $\mathrm{Ca}^{2+}$ -} stimulated $\mathrm{AC}$ activity in the striatum

Messenger RNA for AC5, a cyclase normally inhibited by $\mathrm{Ca}^{2+}$ (Katsushika et al., 1992), has been shown to be selectively localized in striatal neurons (Glatt and Synder, 1993). In agreement with others (Chern et al., 1996), we observed that striatal AC activity was inhibited by $\mathrm{Ca}^{2+}$ in control mice but not in mice that had been trained in either the spatial or the procedural task. The experimental design precludes a trivial explanation for this finding, such as circadian changes in basal levels of AC5 activity (Chern et al., 1996). Low levels of AC1 and AC8 messenger RNA have also been detected in the striatum (Mons et al., 1993; Cali et al., 1994). Although it is likely that expression of these ACs was enhanced by the behavioral experience, it is also possible that $\mathrm{Ca}^{2+}$-stimulated ACs localized presynaptically in corticostriatal inputs were affected by training. Because several $\mathrm{Ca}^{2+}$-sensitive $\mathrm{AC}$ isoforms are present in the striatum, it seems reasonable to suggest that behavioral experience produced a differential change in one of these, such as AC1 or AC5. Further studies will be necessary to resolve this issue.

\section{Dissociation between hippocampal $\mathrm{Ca}^{2+}$-insensitive and $\mathrm{Ca}^{2+}$-stimulated $\mathbf{A C}$ activity after spatial learning}

On the whole, we found that the AC activity was enhanced after both procedural and spatial learning, with lower amplitudes after the latter. One could therefore argue that both tasks rely on similar types of processing and hence induced similar changes in $\mathrm{AC}$ activity. The quantitative variation in the biochemical results could, in this case, be attributed to differences between the mastery of the task in the two training conditions. However, our results show that, in the hippocampus, the changes in AC activity are also qualitative and depend on the type of stimulation used. AC activity measured in the presence of $\mathrm{FK}$, a nonselective stimulator of the AC types, was found to be more greatly increased after procedural training, whereas $\mathrm{Ca}^{2+}$-stimulated activity (type-selective) was more greatly increased after spatial training. Because hippocampal $\mathrm{Ca}^{2+}$-stimulated AC activity was also increased in the procedural group, two possibilities must be considered to explain the differential results for the two training paradigms.

First, it is possible that the activity of both $\mathrm{Ca}^{2+}$-stimulated and $\mathrm{Ca}^{2+}$-insensitive ACs were increased after procedural training, whereas only $\mathrm{Ca}^{2+}$-stimulated ACs were affected by spatial training. Latent spatial learning could also explain why the activity of $\mathrm{Ca}^{2+}$-sensitive ACs in the hippocampus was higher in the procedural group than in naive controls. This would suggest a specific role for hippocampal $\mathrm{Ca}^{2+}$-stimulated $\mathrm{ACs}$ (AC1 and/or AC8) in spatial information processing and is consistent with the 
hypothesized common role for $\mathrm{Ca}^{2+}$-stimulated ACs in mammals and invertebrates (Xia et al., 1995). Second, changes in both $\mathrm{Ca}^{2+}$-insensitive and $\mathrm{Ca}^{2+}$-stimulated $\mathrm{ACs}$ may have taken place in both learning paradigms, but the direction of change in one group of ACs was different from in the other.

Basal AC activity in the hippocampus was not different after spatial and procedural learning, although opposite changes were revealed in a dose-dependent manner by $\mathrm{FK}$ and $\mathrm{Ca}^{2+}$ stimulation, respectively. Because the forskolin signal reflects both $\mathrm{Ca}^{2+}$-insensitive and $\mathrm{Ca}^{2+}$-sensitive activity, a specific explanation for this observation is that one or several $\mathrm{Ca}^{2+}$-insensitive AC isoforms were downregulated by spatial learning. This possibility is in accordance with earlier results showing a decrease in FK-stimulated hippocampal AC activity (in the absence of change in the basal AC activity) after training in a radial arm maze spatial discrimination task (Guillou et al., 1994, 1998). Thus, we favor the explanation that $\mathrm{Ca}^{2+}$-stimulated ACs were enhanced by spatial learning in the hippocampus, whereas $\mathrm{Ca}^{2+}$ insensitive ACs were decreased.

$\mathrm{AC} 1\left(\mathrm{Ca}^{2+}\right.$-stimulated $)$ and $\mathrm{AC} 2\left(\mathrm{Ca}^{2+}\right.$-insensitive $)$ are both dominantly expressed in the hippocampus. AC1 has been suggested to be a good candidate for involvement in neuroplasticity mechanisms, in agreement with a role in long-term potentiation (Storm et al., 1998; Villacres et al., 1998). The present results, showing an enhanced sensitivity of the hippocampal AC activity to $\mathrm{Ca}^{2+}$ after spatial training, support the idea that $\mathrm{AC} 1$ could be a key molecule involved in the spatial mapping function of the hippocampal formation. On the other hand, AC2 is the obvious candidate for downregulation after spatial learning. However, it was recently found that messenger RNA for AC9 is also highly concentrated in the hippocampal formation (Antoni et al., 1998a). Interestingly, AC9 is indirectly inhibited by $\mathrm{Ca}^{2+}$ via the activation of calcineurin (Antoni et al., 1998b). Little is currently known about precise subcellular locations of ACs. However, if $\mathrm{AC} 1$ and $\mathrm{AC} 9$ are colocalized in the hippocampal neurons, as is likely to be the case, one would expect that increases in intracellular concentrations of $\mathrm{Ca}^{2+}$ would activate AC1 while inhibiting AC9. If cAMP is an essential signal for neuroplasticity mechanisms to take place and to allow spatial learning, inhibitory effects of $\mathrm{Ca}^{2+}$ on AC9 activity should be inactivated. Therefore, a decrease of AC9 expression and/or its functionality might be expected during spatial learning.

\section{Conclusion}

The present findings show that the AC activity is altered by learning in a task-dependent manner. Selective patterns of changes, in both $\mathrm{Ca}^{2+}$-sensitive and $\mathrm{Ca}^{2+}$-insensitive $\mathrm{ACs}$, are detected in brain regions that are considered to subserve different forms of learning. Further experiments should permit identification of the $\mathrm{AC}$ isoforms that are involved. However, it is now clear that a complete understanding of the role of ACs in learning and memory in the mammalian brain will not be achieved without considering not only the presence of various AC isoforms but also the existence of multiple memory and brain systems and the way these systems interact in a normal brain.

\section{REFERENCES}

Ahlijanian MK, Cooper DMF (1988) Distinct interactions between $\mathrm{Ca}^{2+} /$ calmodulin and neurotransmitter stimulation of adenylate cyclase in striatum and hippocampus. Cell Mol Neurobiol 8:459-469.

Antoni FA, Palkovits M, Simpson J, Smith SM, Leitch AL, Rosie R, Fink G, Paterson JM (1998a) $\mathrm{Ca}^{2+} /$ calcineurin-inhibited adenylyl cyclase, highly abundant in forebrain regions, is important for learning and memory. J Neurosci 18:9650-9661.

Antoni FA, Smith SM, Simpson J, Rosie R, Fink G, Paterson JM (1998b) Calcium control of adenylyl cyclase: the calcineurin connection. Adv Second Messenger Phosphoprotein Res 32:153-172.

Bernabeu R, Bevilaqua L, Ardenghi P, Bromberg E, Schmitz P, Bianchin M, Izquierdo I, Medina JH (1997) Involvement of hippocampal cAMP/cAMP-dependent protein kinase signaling pathways in a late memory consolidation phase of aversively motivated learning in rats. Proc Natl Acad Sci USA 94:7041-7046.

Cali JJ, Zwaagstra JC, Mons N, Cooper DMF, Krupinski J (1994) Type VIII adenylyl cyclase. A $\mathrm{Ca}^{2+} /$ calmodulin-stimulated enzyme expressed in discrete regions of rat brain. J Biol Chem 269:12190-12195.

Chern Y, Lee EHY, Lai HL, Wang HL, Lee YC, Ching YH (1996) Circadian rhythm in the $\mathrm{Ca}^{2+}$-inhibitable adenylyl cyclase activity of the rat striatum. FEBS Lett 385:205-208.

Cooper DMF, Mons N, Fagan K (1994) $\mathrm{Ca}^{2+}$-sensitive adenylyl cyclases. Cell Signalling 6:823-840.

Cooper DMF, Mons N, Karpen JW (1995) Adenylyl cyclases and the interaction between calcium and cAMP signalling. Nature 374:421-424.

DiMattia BD, Kesner RP (1988) Spatial cognitive maps: differential role of parietal cortex and hippocampal formation. Behav Neurosci 102:471-480

Dudai Y, Jan YN, Byers D, Benzer S (1976) Dunce, a mutant of Drosophila deficient in learning. Proc Natl Acad Sci USA 73:1684-1688.

Eichenbaum H, Otto T, Cohen NJ, (1994) Two functional components of the hippocampal memory system. Behav Brain Sci 17:449-518.

Glatt CE, Snyder SH (1993) Cloning and expression of an adenylyl cyclase localized to the corpus striatum. Nature 361:536-538.

Guillou JL, Micheau J, Jaffard R, (1994) L'hippocampe comme site d'interaction entre les systemes de mémoire [The hippocampus as a site of interaction between memory systems]. C R Seances Soc Biol Fil 188:265-271.

Guillou JL, Micheau J, Jaffard R (1998) The opposite effects of cysteamine on the acquisition of two different tasks in mice are associated with bidirectional testing-induced changes in hippocampal adenylyl cyclase activity. Behav Neurosci 12:900-908.

Jarrard LE (1993) On the role of the hippocampus in learning and memory in the rat. Behav Neural Biol 60:9-26.

Kandel ER, Schwartz JH (1982) Molecular biology of learning: modulation of transmitter release. Science 218:433-443.

Katsushika S, Chen L, Kawabe J, Nilakantin R, Homcy CJ, Ishikawa Y (1992) Cloning and characterization of a sixth adenylyl cyclase isoform: type $\mathrm{V}$ and VI constitute a subgroup within mammalian adenylyl cyclase family. Proc Natl Acad Sci USA 89:8774-8778.

Knowlton BJ, Mangels JA, Squire LR (1996) A neostriatal habit learning system in humans. Science 273:1399-1402.

Kolb B, Walkey J (1987) Behavioural and anatomical studies of the posterior parietal cortex in the rat. Behav Brain Res 23:127-145.

Lowry OH, Rosebrough NJ, Farr AL, Rondall RJ (1951) Protein measurement with the Folin phenol reagent. J Biol Chem 193:265-275.

McHugh Sutkowski E, Tang WJ, Broome CW, Robbins JD, Seamon KB (1994) Regulation of forskolin interactions with type I, II, V and VI adenylyl cyclases by Gs $\alpha$. Biochemistry 33:12852-12859.

Mons N, Cooper DMF (1995) Adenylate cyclases: critical foci in neuronal signaling. Trends Neurosci 12:536-542.

Mons N, Yoshimura M, Cooper DMF (1993) Discrete expression of $\mathrm{Ca}^{2+}$-calmodulin-sensitive and $\mathrm{Ca}^{2+}$-insensitive adenylyl cyclases in the rat brain. Synapse 14:51-59.

Mons N, Decorte L, Jaffard R, Cooper DMF (1998) $\mathrm{Ca}^{2+}$-sensitive adenylyl cyclases, key integrators of cellular signalling. Life Sci 62:1647-1652.

Morris RG, Garrud P, Rawlins JN, O'Keefe J (1982) Place navigation is impaired in rats with hippocampal lesions. Nature 297:681-683.

Morris RG, Hagan JJ, Rawlins JN (1986) Allocentric spatial learning by hippocampectomised rats: a further test of the "spatial mapping" and "working memory" theories of hippocampal function. Q J Exp Psychol B Comp Physiol Psychol 38:365-395.

Moser MB, Moser EI, Forrest E, Andersen P, Morris RG (1995) Spatial learning with a minislab in the dorsal hippocampus. Proc Natl Acad Sci USA 92:9697-9701.

O'Keefe J, Nadel L (1978) The hippocampus as a cognitive map. Oxford: Clarendon.

Packard MG, Hirsh R, White NM (1989) Differential effects of fornix 
and caudate nucleus lesions on two radial maze tasks: evidence for multiple memory systems. J Neurosci 9:1465-1472.

Salomon Y, Londos C, Rodbell M (1974) A highly sensitive adenylate cyclase assay. Anal Biochem 58:541-548.

Save E, Poucet B, Foreman N, Buhot MC (1992) Object exploration and reactions to spatial and nonspatial changes in hooded rats following damage to parietal cortex or hippocampal formation. Behav Neurosci 106:447-456.

Schacter DL, Tulving E (1994) Memory systems. Cambridge, MA: MIT.

Squire LR (1992) Memory and the hippocampus: a synthesis from findings with rats, monkeys and humans. Psychol Rev 99:195-231.

Storm DR, Hansel C, Hacker B, Parent A, Linden DJ (1998) Impaired cerebellar long-term potentiation in type I adenylyl cyclase mutant mice. Neuron 20:1199-1210.

Sutherland RJ, Rudy JW (1989) Configural association theory: the role of the hippocampal formation in learning, memory, and amnesia. Psychobiology 17:129-144.
Thompson RF, Kim JJ (1996) Memory systems in the brain and localization of a memory. Proc Natl Acad Sci USA 93:13438-13444.

Villacres EC, Wong ST, Chavkin C, Storm DR (1998) Type I adenylyl cyclase mutant mice have impaired mossy fiber long-term potentiation. J Neurosci 18:3186-3194.

White NM (1997) Mnemonic functions of the basal ganglia. Curr Opin Neurobiol 7:164-1699.

Wu ZL, Thomas SA, Villacres EC, Xia Z, Simmons ML, Chavkin C, Palmiter RD, Storm DR (1995) Altered behavior and long-term potentiation in type I adenylyl cyclase mutant mice. Proc Natl Acad Sci USA 92:220-224.

Xia Z, Refdal CD, Mercant KM, Dorsa DM, Storm DR (1991) Distribution of mRNA for the calmodulin-sensitive adenylate cyclase in rat brain: expression in areas associated with learning and memory. Neuron 6:431-443.

Xia Z, Choi EJ, Blazynski C, Storm DR (1995) Do the calmodulinstimulated adenylyl cyclases play a role in neuroplasticity? Behav Brain Sci 18:429-440. 